\title{
Natural Disasters Impacting a Macroeconomic Model with Endogenous Dynamics
}

\author{
Stéphane Hallegatte ${ }^{\mathrm{a}, \mathrm{b}}$, Michael Ghil ${ }^{\mathrm{c}, \mathrm{d}}$, \\ ${ }^{a}$ Centre International de Recherche sur l'Environnment et le Développement, \\ Paris, France \\ ${ }^{\mathrm{b}}$ Ecole Nationale de la Météorologie, Météo-France, Toulouse, France \\ c Département Terre-Océan-Atmosphère and Environmental Research and Teaching \\ Institute, Ecole Normale Supérieure, Paris, France \\ ${ }^{\mathrm{d}}$ Department of Atmospheric and Oceanic Sciences and Institute of Geophysics and \\ Planetary Physics, University of California, Los Angeles, CA 90095-1565, USA
}

\begin{abstract}
We investigate the macroeconomic response to natural disasters by using an endogenous business cycle (EnBC) model in which cyclical behavior arises from the investment-profit instability. Our model exhibits a larger response to natural disasters during expansions than during recessions. This apparently paradoxical result can be traced to the disasters amplifying pre-existing disequilibria during expansions, while the existence of unused resources during recessions damps the exogenous shocks. It thus appears that high-growth periods are also highly vulnerable to supply-side shocks. In our EnBC model, the average production loss due to a set of disasters distributed at random in time is highly sensitive to the dynamical characteristics of the impacted economy. Larger economic flexibility allows for a more efficient and rapid response to supply-side shocks and reduces production
\end{abstract}


losses. On the other hand, too high a flexibility can lead to vulnerability phases that cause average production losses to soar. These results raise questions about the assessment of climate change damages or natural-disaster losses that are based purely on long-term growth models.

Key words: Macroeconomic dynamics, Nonequilibrium modeling, Business cycles, Investment flexibility, Natural hazards

\section{Introduction and motivation}

Benson and Clay (2004), among others, have suggested that the overall cost of a natural disaster might depend on the pre-existing economic situation. As an example, the Marmara earthquake in 1999 caused destructions that amounted to between 1.5 and 3 percent of Turkey's Gross Domestic Product (GDP); its cost in terms of production loss, however, is believed to have been kept at a relatively low level by the fact that the country was experiencing a strong recession of $-7 \%$ of GDP in the year before the disaster (World Bank, 1999). The recovery effect from the additional activity due to reconstruction might, in fact, have compensated, at least partly, the direct damages of the disaster. Investigating this problem requires one to model economic fluctuations, and macroeconomists are still quite divided on how best to do this.

Economists have been aware of certain cyclical characteristics of economic evolution since the works of A. Smith (1776), D. Ricardo (1810), C. Juglar (1862) and many others. Two main theories have attempted, over the years,

^ Corresponding author S. Hallegatte.

Email address: hallegatte@centre-cired.fr (Stéphane Hallegatte). 
to explain the causes and characteristics of business cycles. The dominant one today is known as real business cycle $(R B C)$ theory and is implemented within Stochastic Dynamic General Equilibrium models. It originates from the works of Slutsky (1927) and Frisch (1933), which Kydland and Prescott (1982) embedded into the general equilibrium framework with rational expectations. This theory assumes that economic fluctuations arise from exogenous shocks and that the economic system is otherwise stable. The second one is Endogenous Business Cycle (EnBC) theory, which proposes that economic fluctuations are due to intrinsic processes that endogenously destabilize the economic system (e.g., Kalecki, 1937; Harrod, 1939; Kaldor, 1940; Samuelson, 1939; Hicks, 1950; Goodwin, 1967; Day, 1982; Grandmont, 1985; Chiarella et al., 2005). Both theories have their successes and shortcomings, but it is RBC theory that garners consensus in the current economic literature.

The existence of these two alternative theories of economic fluctuations is a significant obstacle in attempting to assess the economic cost of natural disasters, such as hurricanes or earthquakes, or of other exogenous shocks, e.g., the implementation of climate policies aimed at reducing the emissions of greenhouse gases. Indeed, to carry out such an assessment, one has to decide first within which macroeconomic setting to work, as the underlying economic hypotheses can strongly influence the results. Overcoming the controversy between the RBC and EnBC theories and achieving a constructive synthesis between the two would thus reduce in a significant manner uncertainties in the assessment of disaster and policy costs. On the other hand, investigating the consequences of exogenous shocks, like natural disasters, can also provide useful insights into economic behavior in general and help achieve a unified theory of business cycles. The validation of RBC and EnBC models against 
the history of past disasters could provide evidence in support of such a unified theory.

The purpose of the present paper is to explore interaction between economic fluctuations and natural disasters in the EnBC framework. To do so, we apply the Non-Equilibrium Dynamic Model (NEDyM) of Hallegatte et al. (2007a), which exhibits business cycles that reproduce several realistic features of the historical data. We introduce into this model the disaster-modeling scheme of Hallegatte et al. (2007b), in which natural disasters destroy the productive capital through the use of a modified production function and in which reconstruction investments are explicitly represented. In the latter paper, however, disasters were investigated in an economy initially at equilibrium. The main contribution of the present article is to consider a fluctuating economy, and to investigate the sensitivity of the economic consequences of natural disasters with respect to the phase of the business cycle.

In the next section, we summarize the main features of NEDyM, while emphasizing the role of investment flexibility in the model solutions' behavior. In Section 3, we use NEDyM to show that the particular phase of a business cycle matters greatly in assessing the economic impacts of natural disasters. In our EnBC model, this impact is enhanced by internal economic processes when the shock occurs during an expansion phase, while the opposite is the case during a recession. In Section 4, we highlight the high sensitivity of the average production loss caused by a set of disasters, distributed at random in time, with respect to the dynamical characteristics of the impacted economy. Concluding remarks follow in Section 5, and two appendices provide details on NEDyM and on modeling economic impacts of natural disasters. 


\section{Endogenous business cycles (EnBC) theory}

There are few, if any, highly complex systems that exhibit stable behavior.

Most physical and biological systems are characterized by natural variability, i.e. they include destabilizing processes that make them deviate from equilibrium; limitations on resources, on the other hand, cause these deviations to remain bounded in amplitude. Examples of such systems are the global climate system (Ghil et al., 1985) or regional ecosystems dominated by predator-prey interactions (Maynard Smith and Slatkin, 1973; Samuelson, 1974).

Concerning the coupled ocean-atmosphere system, both short-term weather and longer-term climate variability arise from the interaction between the variability of exogenous forcing and the interplay of nonlinear feedbacks (Ghil, 1994, 2002). Variations of external factors do play a key role in the variability: indeed, the diurnal and seasonal cycles steer a large part of this variability and are clearly visible in the power spectrum of meteorological and oceanographic variables. Nonlinear feedbacks in the climate system though — such as those between cloud cover or surface properties and radiative fluxes — are essential drivers of long-term and large-scale variability, even in the absence of exogenous forcing variations.

The same interaction can be observed in ecosystems. Loeuille and Ghil (2004) compared intrinsic (endogenous) and climatic (exogenous) factors in the population dynamics of North American mammals. They found that both types of factors have to be taken into account to understand the behavior of animal populations in time. Again, variability arises from the interplay of nonlinear, endogenous dynamics and responses to exogenous shocks. 
It stands to reason that a similar, combined explanation may be proposed for economic fluctuations and business cycles. Exogenous real shocks clearly do play an important role in business cycles; e.g., the strong economic expansion of the late 1990s was obviously driven by the rapid development of new technologies. Increasing interest in RBC models since the work of Kydland and Prescott (1982) has led to quite faithful matches between multi-variable, detailed versions of such models and actual historical data, which have been compiled and become available during this time interval (e.g., King and Rebelo, 2000).

But denying any role to endogenous fluctuations, due to instabilities and nonlinear feedbacks within the economic system itself, seems rather unrealistic, too. Even within the neoclassical tradition, with perfect markets and rational expectations, Day (1982), Grandmont (1985), Gale (1973), and Benhabib and Nishimura (1979) proposed models in which endogenous fluctuations arise from savings behavior, wealth effects and interest-rate movement, or from interactions between overlapping generations and between different sectors.

Market frictions, imperfect rationality in expectations or aggregation biases can give rise to strongly destabilizing processes within the economic system. Numerous authors have proposed accounting for such processes and noted their importance. Harrod (1939) stated that the economy was unstable because of the absence of an adjustment mechanism between population growth and labor demand, although Solow (1956) suggested later that such a mechanism was provided by the producer's choice of the labor-capital intensity. Kalecki (1937) and Samuelson (1939) proposed simple business cycle models based on a Keynesian accelerator-multiplier and delayed investments. Later on, Kaldor (1940), Hicks (1950) and Goodwin (1951, 1967) developed busi- 
ness cycle models in which the destabilizing process was still the Keynesian accelerator-multiplier and the stabilizing processes were financial constraints, distribution of income or the role of the reserve army of labor. In Hahn and Solow (1995, chapter 6), fluctuations can arise from an imperfect goods market, from frictions in the labor market, and from the interplay of irreversible investment and monopolistic competition.

EnBC theory was studied quite actively in the middle of the 20th century but much less so over the last quarter century or so. Still, Hillinger (1992), Jarsulic (1993), Flaschel et al. (1997), Nikaido (1996), Chiarella and Flaschel (2000), Chiarella et al. (2005) and Hallegatte et al. (2007a), among many others, have recently proposed EnBC models and further investigated their properties. The business cycles in these models arise from nonlinear relationships between economic aggregates and are consistent with certain realistic features of actual business cycles.

The relatively limited recent interest in EnBC models has led to less progress being made so far in matching their results to the historical data that have been used much more actively in studying RBCs. Even so, Chiarella et al. (2006) show that their model is able to reproduce historical series when utilization data are taken as input. It is not surprising, moreover, that EnBC models with only a few state variables - typically less than a few dozen were unable to reproduce the details of historical information that involves processes lying explicitly outside the scope of an economic model (e.g., geopolitical events).

Hallegatte et al.'s (2007a) NEDyM is a neoclassical model with myopic expectations, in which adjustment delays have been introduced in the clearing 
mechanisms of the labor and goods markets, as well as in the investment response to profitability signals. All model equations are reproduced and explained succintly in Appendix A.

In this model, business cycles originate from the instability of the profitinvestment relationship, a relationship similar to the Keynesian acceleratormultiplier. Furthermore, the cycles are constrained by the interplay of three processes: (i) a reserve army of labor effect, namely the increase of labor costs when the employment rate is high; (ii) the inertia of production capacity and the consequent inflation in goods prices when demand increases too rapidly; and (iii) financial constraints on investment.

The model's main control parameter is the flexibility of investment $\alpha_{i n v}$, which measures the investment adjustment speed in response to profitability signals; see Eq. (A.16) in Appendix A. This parameter describes how rapidly investment can react to a profitability signal: if $\alpha_{i n v}$ is very small, investment decreases very slowly when profits are small; if $\alpha_{i n v}$ is very large, investment soars when profits are high and collapses when profits are small. Introducing this parameter is an equivalent alternative to the investment adjustment cost proposed by, e.g., Kydland and Prescott (1982) and Kimball (1995). These authors find that introducing adjustment costs and delays helps enormously in allowing macroeconomic models match key features of the data.

The NEDyM investment flexibility summarizes many characteristics of an economy, and differences in $\alpha_{i n v}$ can arise from many factors:

- First, investing more requires producing more investment goods, and this cannot be done instantaneously (e.g., the famous "time of build" of Kydland and Prescott, 1982). The ability of an economy to modify its produc- 
tion structure is, therefore, essential to determine investment flexibility. Of course, different economic structures lead to different investment flexibility. This fact is highlighted in Ireland (2003), who shows that the capital adjustment cost in the U.S. is changing over time because of structural economic changes. As an example, investments in service sectors are much more flexible than in industrial sectors, because the industrial sectors are highly specialized and capitalized, with investments that require very specific goods and services. The production of these investments goods cannot be increased rapidly in response to changes in economic conditions. The electricity sector is a good example: if more investments are profitable in this sector, it means that more electricity plants and distribution infrastructure will have to be produced, which cannot be done is less than a few years. Investments in personal services, on the other hands, consist of small equipments, the production of which is much more flexible. Also, installed capital in industrial sectors is not flexible and cannot be easily retrofitted to be used for different purposes or in different sectors: a chemical plant cannot be used in another sector, while the facilities and computers that are used in service sectors can be used in any other sector. As a consequence of these sources of inertia in industrial sectors, a rise in profitability in these sectors may not lead to an immediate increase in investments, as is possible in other sectors. This determinant of investment flexibility tends to reduce investment flexibility in industrialized countries, compared with developing countries.

- Second, what is true for the productive capital is also valid for human capital. In sectors in which workers have very specialized skills, it may be impossible to satisfy an increase in demand, because of skilled-worker scarcity. This lack of workers may make it useless to invest in additional capital, 
until the required workers are available (e.g., thanks to training and continuing education). The higher level of specialization in development countries tends to reduce their flexibility, compared with developing countries. On the other hand, the higher education level in developed-country populations helps workers shift from one sector to another, increasing the economic flexibility and the ability of produce the needed investment goods (e.g., Lanzi, 2007).

- Third, differences in capital market and financial situation can explain differences in investment flexibility at the firm level (see, e.g., Gertler and Hubbard, 1988; Hu and Schiantarelli, 1998), also making a difference between developed and developing countries. In case of a positive shock in profitability, open countries with well developed and credible financial markets will be able to invest more, thanks to international and domestic borrowing. In other countries, investments may be limited by available financing opportunities.

- Fourth, investment flexibility depends on company management and cultural factors. For instance, some businesses and companies are managed as a function of longer term objectives than others, depending on the ownership structure and on financial-market norms (e.g., Jensen, 1986). Obviously, companies managed with short-term objectives will react in a stronger manner to changes in profitability. Investment flexibility, therefore, can be different in countries with different types of ownership (e.g., family ownership is more frequent in Europe than in the U.S.).

In NEDyM, investment flexibility has a major influence of economic dynamics. For small $\alpha_{i n v}$, i.e. slow adjustment, the model has a stable equilibrium, which was matched to the economic state of the European Union (EU-15) in 

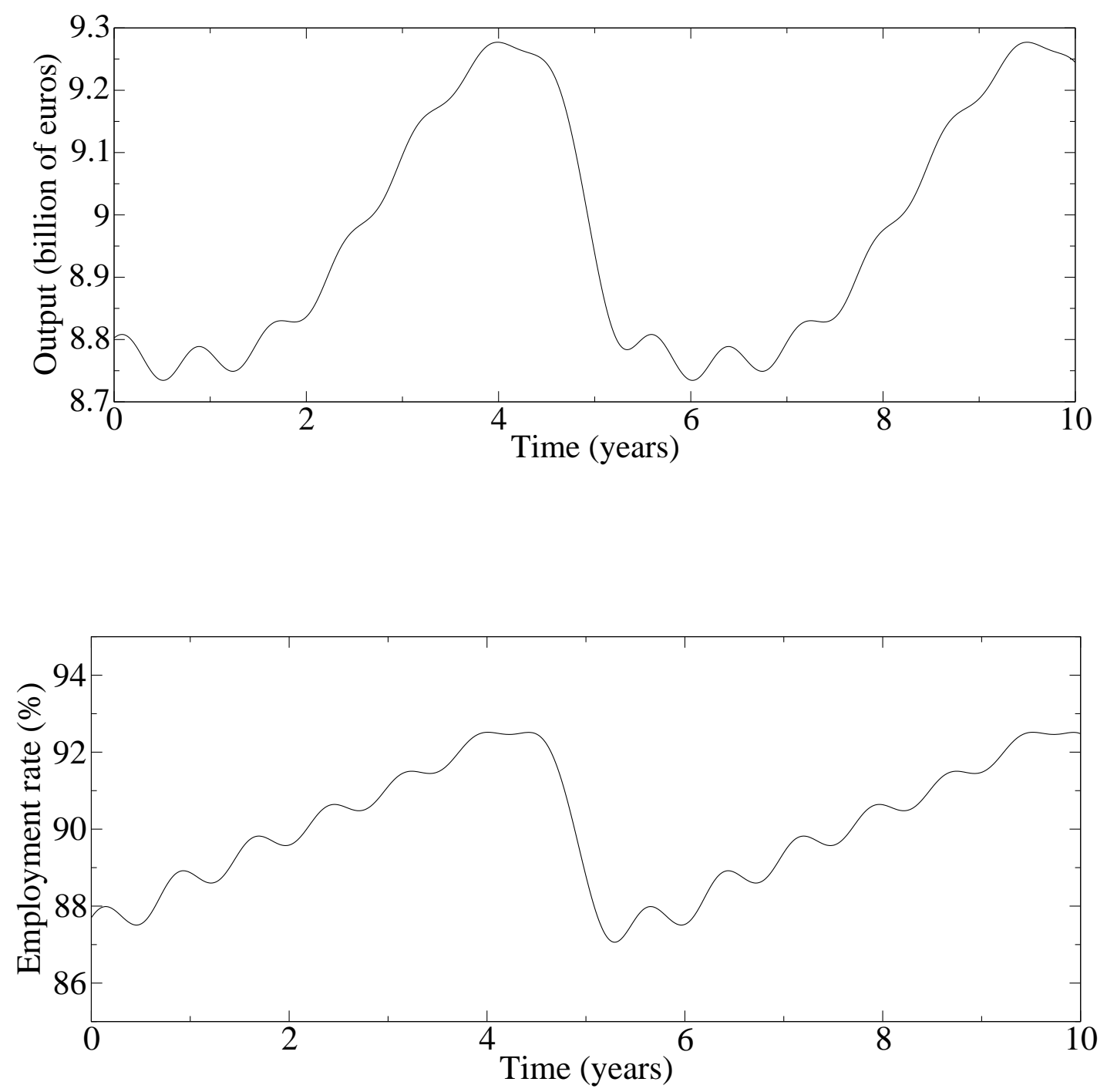

Fig. 1. Endogenous business cycle reproduced by the NEDyM model with a flexibility of investment $\alpha_{i n v}=2.5$, in terms of output (top panel) and employment (bottom panel); time in years, starting at the end of the recession. After Hallegatte et al. (2007a).

2001. As the adjustment flexibility increases, this equilibrium loses its stability and the model then possesses a stable periodic solution; this "limit cycle," in the language of dynamical systems (Guckenheimer and Holmes, 1987), is characterized by variables that oscillate around their equilibrium values. 
The business cycle produced by the model with $\alpha_{i n v}=2.5$ is shown in Fig. 1 and it is far from perfect, in particular because the amplitude of the oscillation in monetary variables is too large. The latter shortcoming of the NEDyM model is due to the fact that market adjustments are entirely made through prices in the model; this model feature can be corrected by introducing, following Gali (1999), quantities in the behavioral equations (investment decisions, employment decisions by employers, utilization rate, etc.) and we shall do so in a subsequent paper. Most observed qualitative features, though, are fairly well reproduced: the mean period is 5-6 years, the recessions are much more rapid than the expansions, inflation is well correlated with production, and the phase relations between variables are generally correct. Another interesting feature of the model's business cycles is that the expansion phases exhibit shorter-period perturbations, whereas the recessions are quite smooth.

\section{$3 \quad$ Natural disasters and endogenous dynamics}

EnBC models have not reproduced, so far, a perfectly realistic business cycle and, therefore, have not been able to provide realistic estimates of real or monetary economic variables. These models, however, can help us understand the interactions between exogenous shocks, like natural disasters, and endogenous dynamics.

To investigate these interactions, we use the NEDyM model with a value of the investment flexibility $\alpha_{i n v}=2.5$, for which the model exhibits perfectly periodic business cycles, cf. Fig. 1 above. We introduce into this model the disaster-modeling scheme of Hallegatte et al. (2007b), which is described in Appendix B. In this scheme, (i) natural disasters destroy the productive capital 
through the use of a modified production function ${ }^{1}$; and (ii) reconstruction expenditures are limited to a given fraction $f_{\max }$ of total investments. The latter assumption accounts for the fact that economic frictions and constraints reduce the ability of a given economy to mobilize resources and carry out the reconstruction work. Hallegatte et al. (2007b) have shown that, without these constraints, complete reconstruction only requires a couple of months, even for large-scale disasters, a result that is at odds with past experience.

In our modeling framework, as in most real cases (Albala-Bertrand, 1993; Tavares, 2004), the economic shocks induced by natural disasters are one or two orders of magnitude smaller than observed economic fluctuations.

To evaluate how the cost of a disaster depends on the pre-existing economic situation, we apply the same loss of productive capital at different points in time along the models business cycle. To assess the total GDP loss, we use the difference between the 20-year total production in a baseline scenario, with no disaster, and the 20-year total production in the disaster scenario; no discounting was applied in assessing this difference.

The top panel of Fig. 2 shows the model's business cycle as a function of time, starting at the end of recession. The bottom panel shows the overall cost of a disaster that destroys $3 \%$ of GDP, with respect to the time at which the disaster occurs; the latter time is also measured from the end of the recession. The total GDP losses caused by the disaster depend strongly on the phase of the business cycle during which the disaster occurs: the cost is minimal if the event occurs at the end of the recession and it is maximal if the disaster

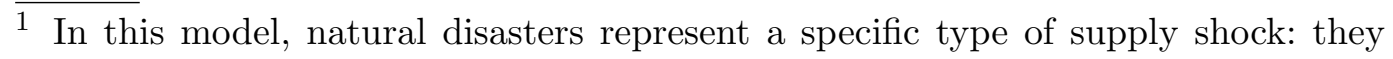
impact productive capital, rather than productivity, like in typical RBC models. 

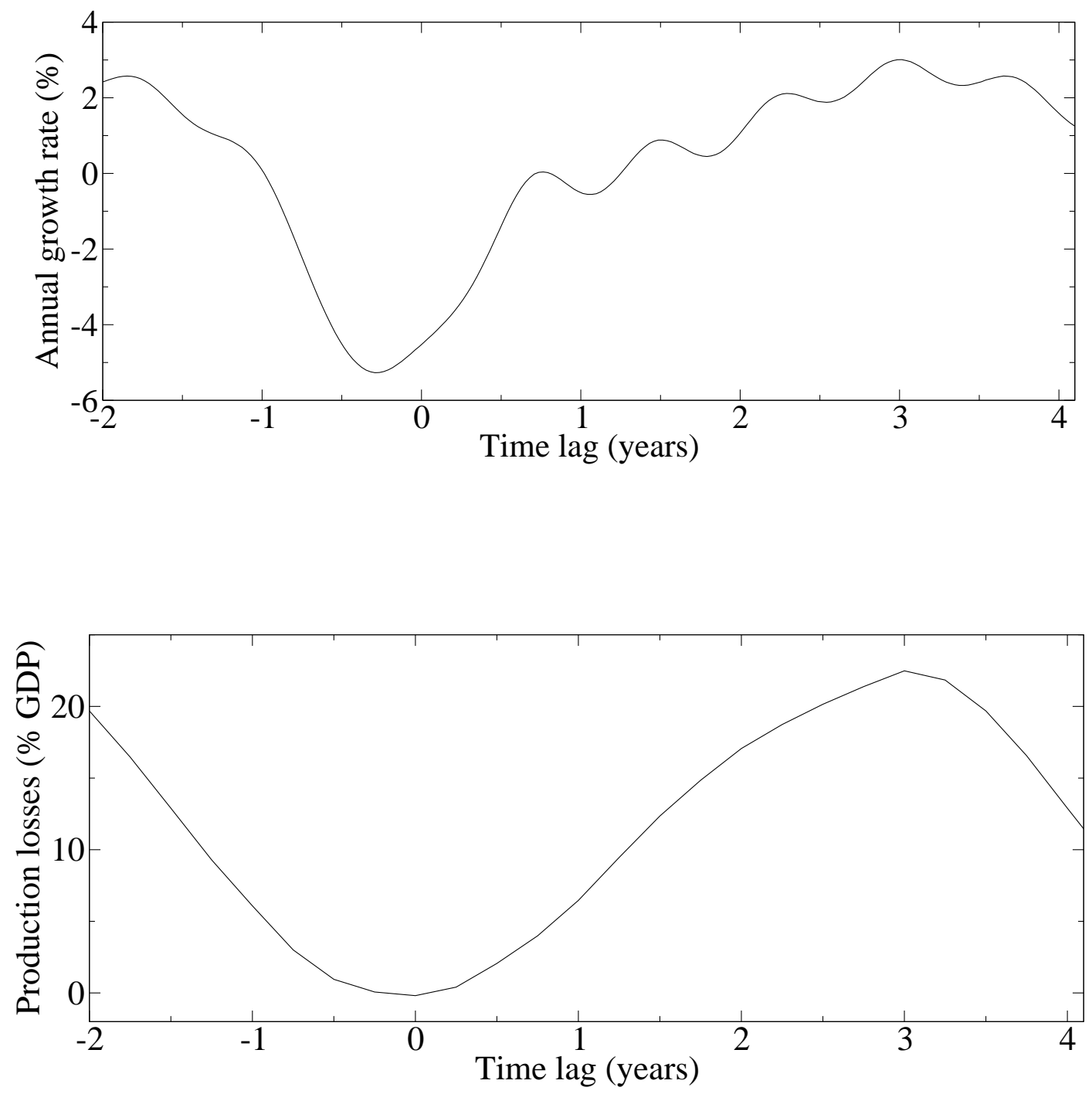

Fig. 2. The effect of one natural disaster on an endogenous business cycle. Top panel: the business cycle in terms of annual growth rate, as a function of time, starting at the cycle minimum (time lag=0). Bottom panel: total GDP losses due to one disaster, as a function of the cycle phase in which it occurs, measured as a time lag with respect to the cycle minimum. A disaster occurring at the cycle minimum causes a limited production loss, while a disaster occurring during the expansion leads to a much larger production loss.

occurs in the middle of the expansion phase, when the growth rate is largest.

There is, therefore, a "vulnerability paradox": 
- A disaster that occurs when the economy is depressed results in lower damages, thanks to the recovery effect of the reconstruction, which activates unused resources. In this situation, since employment is low, additional hiring for reconstruction purposes will not drive the wages up to a significant extent. Moreover, the stock of goods during the recession is also larger than at equilibrium; a disruption of production, therefore, can be damped by inventories. Finally, the investment ratio is low and the financial constraint on it is negligible: the producer can easily increase his/her investment. In this case, the economic response damps the lasting costs of the disaster, according to the model.

- A disaster occurring during the high-growth period, though, results in larger damages, as it enhances pre-existing disequilibria. First, the inventories are below their equilibrium value during the high-growth phase, so they cannot compensate for the reduced production. Second, employment is at a very high level and hiring more employees induces wage inflation. Finally, because the investment ratio is high, the producer lacks financial resources to increase his/her investment. The maximum production loss in the model reaches 20 percent of GDP in Fig. 2. This unrealistically high GDP loss is probably related to the exagerated amplitude of the model's business cycle.

We recall here (see Hallegatte et al., 2007a, and Appendix A of the present paper) that many mechanisms are disregarded in the present version of the model, especially the role of goods imports and exports, which are observed to change in the aftermath of disaster (see Gassebner et al., 2006), and the role of financial aid (Benson and Clay, 2004). It appears, though, that including these mechanisms could change the absolute cost of disasters, but would not change the difference between their costs when a disaster impacts the economy 
at different points of its business cycle; our findings thus seem to be robust to this model shortcoming.

As already mentioned, the present article does not claim to produce accurate cost estimates for a given disaster, only to highlight qualitative mechanisms. These mechanisms can be summarized in a more insightful way. The reconstruction in the disaster's aftermath is equivalent to a positive perturbation of the model's main destabilizing process, namely the profit-investment relationship or Keynesian accelerator-multiplier. The three processes that maintain the model within a bounded domain of its phase space - i.e., maintain its variables within a reasonable range — and compensate for its endogenous instability come, therefore, into play in the same way in response either to an endogenous instability or to an exogenous natural disaster.

These processes are stronger at the end of the growth phase of the business cycle; it comes therefore as no surprise that they impede reconstruction, just as they prevent the expansion phase of the business cycle from lasting forever. It is surprising, however, that this equivalence also causes a robust economy with a high growth rate to be much more vulnerable to natural disasters than a depressed economy that has idle resources in store. Note, though, that this comparison is between distinct phases of its evolution for the same, relatively healthy economy, and not between a weak and a strong economy: damages due to similar natural disasters will always be larger for the former than for the latter (Albala-Bertrand, 1993; Benson and Clay, 2004).

This apparently paradoxical effect, however, is consistent with Keynes' (1936) ideas, when he described his well-known strategy to get out of a depression: "If the Treasury were to fill old bottles with banknotes, bury them at suitable depths 
in disused coalmines which are then filled up to the surface with town rubbish, and leave it to private enterprise on well-tried principles of laissez faire to dig the notes up again [...] there need be no more unemployment [...]. It would indeed be more sensible to build houses and the like; but if there are political and practical difficulties in the way of this, the above would be better than nothing." In fact, it is not much different to increase demand through fiscal or budgetary policies than through the destruction of houses and production capital that need to be replaced as rapidly as possible. In the latter situation, agents increase their consumption and reduce their savings, thus leading to a rise in demand ${ }^{2}$. It is also well-known that this approach to macroeconomic stabilization is useless if the supply is constrained, which is the case during the expansion phase of the business cycle.

An empirical measure of this effect may be possible using what is called "demand surge": prices in the construction sector increase significantly in response to the large reconstruction demand in a disaster's aftermath; see a complete analysis on Florida after the 2004 and 2005 hurricane seasons in Hallegatte et al. (2008). Demand surge is thought to originate from the lack of capacity in the economic sectors involved in the reconstruction. For instance, hurricane landfalls are responsible for major damage to house roofs. After a landfall, the affected region has, therefore, a much larger demand for roofer work than usual. Owners of damaged houses have to compete to get qualified workers to repair their roof and this competition leads to inflation in the price of roof repairs. Demand surge, in particular, is a good measure of the tension in the reconstruction process: when demand gets very high, it means that the con-

$\overline{2}$ This shift in savings ratio can be carried out either directly by the agents, or through the intermediary of insurance companies that sell assets to pay claims. 
struction sector cannot cope with the disaster and that the reconstruction period will be longer than normal, and the production losses larger. Also, it means that affected agents will have to pay more to reconstruct their house or to replace their capital.

Obviously, the level of demand surge is much higher when the capacity in the construction sector is fully used before the disaster than when the activity is weak in this sector; this difference should be quite measurable in comparing Florida before the 2004 hurricane season and its four landfalls, when capacity was being fully used, vs. Florida before the landfall of hurricane Andrew in 1992, when the sector was functioning only at 50 percent of its capacity (West and Lenze, 1994). According to data from the insurance industry (A. Boissonnade, personal communication, 2007), the demand surge following Andrew remained limited indeed, considering the scale of the disaster, at around 20 percent, while demand surge reached 40 percent in some regions of Florida in 2004. This difference suggests that the consequences of the 2004 disasters were larger than the consequences of Andrew in 1992, because the U.S. had just come out of a deep recession in 1992, and had therefore idle resources to mobilize for reconstruction, while the country was in a strong expansion phase in 2004 .

As mentioned already, this conclusion is valid only for one and the same economy in different phases of its business cycle. If two economies at different stages of economic development are compared, it is very likely that the poorer one will be more vulnerable because of a large set of other factors. First, poor countries are more vulnerable because the direct losses due to the same disaster are larger there. Indeed, poor countries have a lower capacity to predict the disaster and warn the population, e.g., because of less efficient early warn- 
ing systems and telecommunication infrastructures. Also, they have greater difficulties to fund mitigation and preparedness actions like the construction of flood protection systems, and their housing quality is most of the time poorer than in rich countries. Second, economic processes tend to be less efficient in reducing the consequences of a disaster. Indeed, these countries often struggle to provide post-disaster relief and emergency support to avoid indirect impacts like health problems. Moreover, they have fewer resources to fund reconstruction, and poorer access to insurance and international borrowing. Reconstruction also requires scientific and technical capabilities that are less well developed in poorer countries. Finally, supporting affected businesses during the reconstruction phase to prevent bankruptcies from spreading the shock into the entire economy is very important in disaster aftermaths, and such measures are often too expensive for poor countries.

\section{Distribution of disasters and economic dynamics}

The ultimate cost of a single supply-side shock thus depends on the phase of the business cycle. It is likely, therewith, that the cost of a given distribution in time of natural disasters that affect an economy depends on the characteristics of this economy's dynamics. For instance, two economies that exhibit

fluctuations of different amplitudes would probably cope differently with the same distribution of natural disasters.

To investigate this issue, we used NEDyM to consider different economies of the same size and at the same development stage, which differ only by their investment flexibility $\alpha_{i n v}$. As shown in Hallegatte et al. (2007a), and illustrated in Fig. 3 here, if $\alpha_{i n v}$ if lower than a fixed value 1.39, the model possesses a 


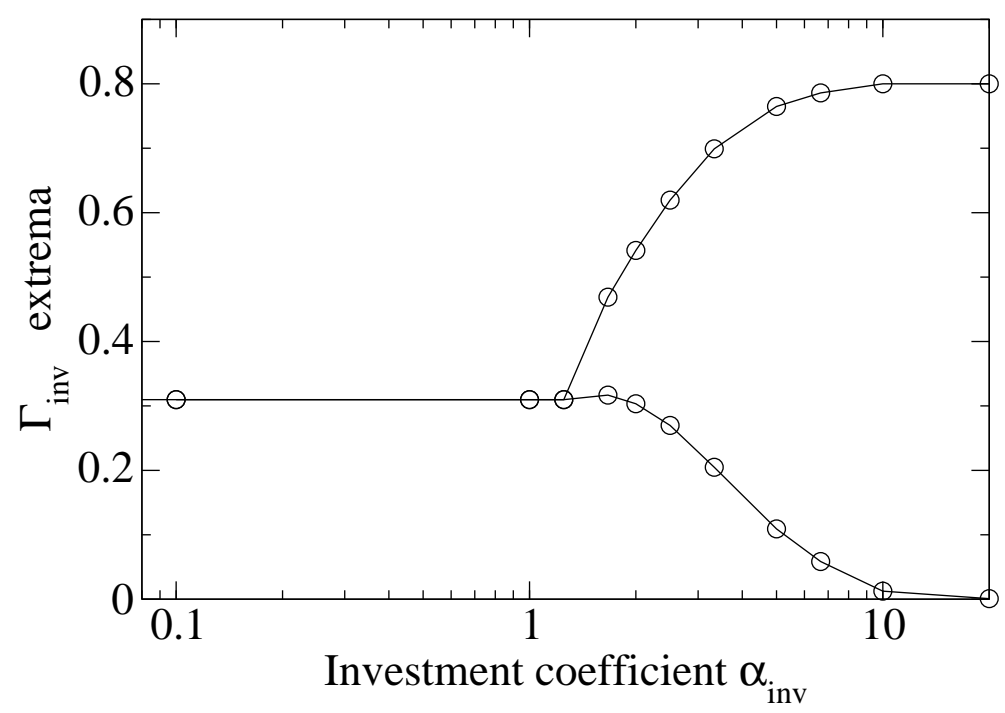

Fig. 3. Extrema of the oscillation in investment ratio $\Gamma_{i n v}$ as a function of the investment flexibility $\alpha_{i n v}$; from Hallegatte et al. (2007a).

single stable equilibrium. Above this value, the model solutions exhibit oscillations of increasing amplitude, as the investment flexibility increases.

We use for illustration purposes the natural disaster distribution of Hallegatte et al. (2007b), which was calibrated on the disasters that impacted the European Union in the last 30 years (Munich Re, 2004). This distribution of events is used here to assess the mean production losses due to natural disasters in the present EnBC model, while Hallegatte et al. (2007b) did so for a stable economy at equilibrium.

The results are reproduced in Table 1 and highlight the very substantial, but complex role of investment flexibility. If investment flexibility is null (first row 


No investment flexibility $\quad$ Stable
\[ \alpha_{i n v}=0.0 \]
Low investment flexibility $\quad$ Stable
\[ \alpha_{i n v}=1.0 \]
High investment flexibility $\quad$ Endogenous business
\[ \alpha_{i n v}=2.5 \]
Table 1
Long-term averaged GDP losses due to the distribution of natural disasters for
different types of economic dynamics.
of the table) or very low (not shown), the economy is incapable of responding
to the natural disasters through investment increases aimed at reconstruction.
Total production losses, therefore, are very large, amounting to $0.15 \%$ of GDP
when the flexibility is null. Such an economy behaves according to a pure
Solow growth model, where the savings, and therefore the investment, ratio is
constant.

When investment can respond to profitability signals without destabilizing the economy, i.e. when $\alpha_{i n v}$ is non-null but still lower than 1.39 , the economy has a new degree of freedom to improve its situation and respond to productivecapital shocks. Such an economy is much more resilient to disasters, because it can adjust its level of investment in the disaster's aftermath: for $\alpha_{i n v}=1.0$ (second row of the table), GDP losses are as low as $0.01 \%$ of GDP, a decrease 
by a factor of 15 with respect to a constant investment ratio, thanks to the added investment flexibility.

If investment flexibility is larger than 1.39 (third row of the table), the economy undergoes an endogenous business cycle and, along this cycle, the economy crosses phases of high vulnerability, as shown in Section 3. As a consequence, production losses due to disasters that occur during expansion phases are largely amplified, while they are reduced when the shocks occur during the recession phase. On average, however, (i) expansions last much longer than recessions, in our NEDyM model and in reality; and (ii) amplification effects are larger than damping effects. It follows that the total effect of the cycle is strongly negative, with an average production loss of $0.12 \%$ of GDP.

These results suggest the existence of an optimal investment flexibility; this flexibility would allow the economy to react in an efficient manner to exogenous shocks, without provoking endogenous fluctuations that would make it too vulnerable to such shocks. According to our model, therefore, stabilization policies may not only help prevent recessions from being too strong and costly; they may also help control expansion phases, and thus prevent the economy from becoming too vulnerable to unexpected shocks, like natural disasters or other supply-side shocks. Examples of the latter are energy-price shocks, like the oil shock of the 1970s, and production bottlenecks, for instance when electricity production cannot satisfy the demand from a growing industrial sector. 


\section{Concluding remarks}

Endogenous business cycle (EnBC) theory explains economic fluctuations first and foremost, but not exclusively — by intrinsic economic mechanisms that destabilize the economy and cause endogenous fluctuations. Numerous models have been built on this premise, in the neoclassical as well as in the Keynesian tradition. Certain EnBC models can reproduce some of the stylized facts of business cycles, even though no such model is able, so far, to reproduce detailed historical data. Real business cycle (RBC) theory assumes that the cycles arise mainly due to productivity shocks acting on a stable economy and has been widely accepted over the last quater-century. Still, RBC models have difficulties in providing a convincing explanation for certain stylized facts

of business cycles, such as the relative length of expansions and brevity of recessions.

We have argued here that underlying modeling hypotheses can strongly influence the results of assessing the macroeconomic impacts of natural hazards and other supply-side shocks. Overcoming the controversy between the RBC and EnBC theories and achieving a constructive synthesis between the two would thus reduce in a significant manner uncertainties in the assessment of disaster and policy costs. Hallegatte et al. (2007b) studied mean production losses due to natural disasters for a stable economy at equilibrium. They used a natural disaster distribution that was calibrated on the disasters having impacted the European Union in the last 30 years. We reconsidered here their assumptions, by using an EnBC model instead.

The EnBC model formulated and initially analyzed by Hallegatte et al. (2007a) 
was briefly summarized in Section 2 and its endogenous business cycles illustrated in Fig. 1. This Non-Equilibrium Dynamical Model (NEDyM) was then used in Section 3 to assess the economic cost of a single natural disaster and the sensitivity of this cost to the pre-existing economic situation. In NEDyM, the cost of a disaster is strongly dependent on the phase of the business cycle in which it occurs (see Fig. 2): while a disaster that occurs at the end of a cycle's recession has a relatively small cost, this cost is greatly increased by economic processes and pre-existing disequilibria when the disaster occurs at a time of rapid growth. There is, therefore, a vulnerability paradox, as a healthy economy with high growth appears to be more vulnerable to disasters than a depressed economy in which some resources are left unused. This conclusion, however, applies only to a given economy and does not extend to the comparison of two distinct economies: an overall flourishing economy is clearly more robust than an economy that is weak overall.

It follows from this EnBC model result that macroeconomic stabilization policies should not only be applied to prevent strong crises. It may also be desirable, given a certain long-term average growth, to prevent periods of growth that is excessive, since various imbalances during such periods can make the economy particularly vulnerable to any supply-side shock, whether natural disasters or sectorial bottlenecks. The crudeness of the present model and its imperfect ability to reproduce realistic business cycle make it impossible to quantify in a precise manner the importance of the differential-sensitivity mechanism we describe. This theoretical and preliminary result, however, calls for more research in the modeling of business cycles and the understanding of the consequences of exogenous shocks impacting out-of-equilibrium economies.

An important consequence of such differential sensitivity is that the mean pro- 
duction loss due to a distribution of natural disasters is strongly dependent on the dynamics of the affected economy. We examined this effect in Section 4, by considering the natural disaster distribution that was calibrated by Hallegatte et al. (2007b) on the disasters having impacted the European Union in the last 30 years. The results in Table 1 highlight the very substantial, but complex role of investment flexibility: GDP losses are high either when there is no such flexibility at all, as in a pure-growth model with constant investment ratio $(0.12 \%$ loss $)$ or when the fexibility is too high, putting the economy through vulnerability phases that make the average cost of a disaster soar $(0.15 \%$ loss $)$. Moderate flexibility seems to be optimal, allowing the economy to respond more rapidly and efficiently to the shock and to reduce its cost, to as little as $0.01 \%$. This result suggests the existence of an optimal flexibility of investments in response to profitability signals.

The present results also support the conclusions of Hallegatte et al. (2007b) that economic damages due to natural disasters depend strongly on economic characteristics and organization. It is impossible, therefore, to estimate the damages from natural disasters without making explicit assumptions about the affected economy.

Hallegatte et al. (2007b) suggested a first set of questions:

- How is reconstruction funded?

- How strong and efficient is the insurance sector?

- Is government-funded support available to help and accelerate reconstruction?

- How long are the delays in providing such support?

- What is the production capacity of the economic sectors involved in recon- 
struction (construction, infrastructures, etc.)?

- How many workers are available to join these sectors in a disaster's aftermath?

The present article emphasizes two new questions:

- How is the economy under study able to adjust its investment level to a shock?

- Does this economy exhibit large fluctuations, with higher-vulnerability phases linked to internal imbalances (inflation, sectorial bottlenecks, lack of workers in reconstruction sectors, etc.)?

These questions and the high sensitivity of the present results to assumptions on the characteristics of economic dynamics raise interesting issues about published assessments of climate change economic damages (e.g., Tol, 2002a, 2002b; Nordhaus, 2006) and of natural-disaster losses (e.g., Bockarjova et al., 2004; Cochrane, 2004; Hallegatte, 2008; Okuyama, 2004; Rose et al., 1997). Indeed, these studies assume equilibrium economies and neglect all adjustment processes and transient imbalances. The possibility of much larger impacts has to be accounted for in the cost-benefit analysis of natural-hazard protection infrastructures or in the design of climate policies.

This paper calls for a research agenda to build a theory of economic fluctuations that would allow us to assess the consequences of interactions between endogenous dynamics and exogenous shocks, like natural or man-made catastrophes. According to our preliminary results, disequilibria and adjustment processes can no longer be entirely neglected in assessing economic losses due to such catastrophes. 


\section{Acknowledgements}

The authors are grateful to Patrice Dumas, Carl Chiarella, Benjamin Malin and two anonymous referees for their useful comments and suggestions on an earlier version of this article. This research was supported by the European Commission's Project No. 12975 (NEST) "Extreme events: Causes and consequences (E2-C2)".

\section{A Appendix: NEDyM, a dynamic model for unbalanced growth}

Our Non-Equilibrium Dynamic Model (NEDyM) is a model that reproduces the behavior of the Solow (1956) model over the long term, but allows for disequilibria during transient periods. A full description and analysis of NEDyM are available in Hallegatte et al. (2007a), but key assumptions and governing equations are reproduced here.

NEDyM models a closed economy, with one representative consumer, one producer, and one good, used both for consumption and investment. The original Solow (1956) model is composed of a static core describing the market equilibrium and a dynamic relationship describing the productive capital evolution. In NEDyM, we translate the static core into dynamic laws of evolution by building delays into the pathways toward equilibrium. This device introduces short-term dynamics into the model.

We explain below the main changes applied to the basic Solow model, starting with its core set of equations where $Y$ is production, $K$ is productive capital, $L$ is labor, $A$ is total productivity, $C$ is consumption, $S$ is consumer savings, 
$I$ is investment, $\Gamma_{i n v}$ is the investment (or, equivalently, saving) ratio, $\tau_{d e p}$ is the depreciation time, and $L_{f u l l}$ is the labor at full employment:

$$
\begin{aligned}
& \frac{d K}{d t}=I-\frac{K}{\tau_{d e p}}, \\
& Y=f(K, L)=A L^{\lambda} K^{\mu}, \\
& C+I=Y, \\
& L=L_{f u l l}, \\
& S=\Gamma_{\text {inv }} Y, \\
& I=S .
\end{aligned}
$$

NEDyM introduces the following changes to this long-term growth model:

(1) Goods market: A goods inventory $H$ is introduced, opening the possibility of temporary imbalances between production and demand, instead of a market clearing at each point in time. Thus

$$
\frac{d H}{d t}=Y-(C+I)
$$

replaces Eq. (A-3) above. This inventory can be either positive or negative $^{3}$ and it encompasses all sources of delay in the adjustment between $\overline{3}$ The goods inventory should be interpreted as the difference with respect to an equilibrium value: a positive value indicates temporary overproduction, while a negative value indicates underproduction. 
supply and demand, including technical lags in producing, transporting and distributing goods. Its situation affects price movements:

$$
\frac{d p}{d t}=-p \cdot \alpha_{\text {price }} \cdot \frac{H}{Y}
$$

Thus price adjustments do not operate instantaneously and the conventional market clearing conditions are verified only over the long term.

(2) Labor market: The producer sets the optimal labor demand $L_{e}$ that maximizes profits, as a function of real wage and marginal labor productivity:

$$
\frac{w}{p}=\frac{d f}{d L}\left(L_{e}, K\right)
$$

But full employment is not guaranteed at each point in time, such as in Eq. (A-4), because (i) institutional and technical constraints create a delay between a change in the optimal labor demand and the corresponding change in the number of actually employed workers:

$$
\frac{d L}{d t}=\frac{1}{\tau_{e m p l}}\left(L_{e}-L\right) ;
$$

and (ii) wages are partially rigid over the short term; they progressively restore the full employment rate by increasing if labor demand is higher than $L_{\text {full }}$, and decreasing when it is lower:

$$
\frac{d w}{d t}=\frac{w}{\tau_{\text {wage }}} \frac{\left(L-L_{\text {full }}\right)}{L_{\text {full }}} .
$$

(3) Household behavior: Like the Solow model, NEDyM uses a constant saving ratio but it makes the tradeoff between consumption and saving in Eq. (A-5) more sophisticated by considering that households (i) consume $C$; (ii) make their savings available for investment through the savings $S$; and (iii) hoard up a stock of money $M$ that is not immediately available 
for investment ${ }^{4}$.

(4) Producer behavior: Instead of automatically equating investments and savings, as in Eq. (A-6), NEDyM describes an investment behavior " $a$ la Kalecki (1937)." It introduces a stock of liquid assets $F$ held by banks and companies, which is filled by the difference between sales $p(C+I)$ and wages $w L$, and by the savings $S$ received from consumers. These assets are used to redistribute share dividends ${ }^{5}$ Div and to invest in the amount $p I$. This formulation creates a wedge between investment and savings, reflected by changs in $F$ :

$$
\frac{d F}{d t}=p(C+I)-w L+S-D i v-p I
$$

The dynamics of the system is governed by an investment ratio that allocates these assets between productive investments and share dividends:

$$
\begin{gathered}
p I=\Gamma_{i n v} \cdot \alpha_{F} F, \\
D i v=\left(1-\Gamma_{i n v}\right) \cdot \alpha_{F} F .
\end{gathered}
$$

The producer's net profit $\Pi_{n}$ follows the accounting definition of profit (Copeland and Weston, 2003), that is gross profits minus capital depreciation:

$\overline{4}$ The existence of this stock $M$ is justified by the preference for liquidity and precautionary savings, as well as by practical constraints; it is needed to carry out the model's economic transactions.

5 In NEDyM the share dividends encompass all investment benefits: dividends, revenues from bonds, sales of assets, capital gains, spin-offs to shareholders, and repurchase of shares. 


$$
\Pi_{n}=\Pi-\frac{1}{\tau_{d e p}} p K=p(C+I)-w L-\frac{1}{\tau_{d e p}} p K,
$$

and the investment ratio follows the prognostic rule:

$$
\frac{d \Gamma_{i n v}}{d t}= \begin{cases}\alpha_{i n v}\left(\gamma_{m a x}-\Gamma_{i n v}\right)\left(\frac{\widetilde{\Pi}_{n}}{p K}-\nu\right) & \text { if } \frac{\widetilde{\Pi}_{n}}{p K}-\nu>0 \\ \alpha_{i n v}\left(\Gamma_{i n v}-\gamma_{m i n}\right)\left(\frac{\widetilde{\Pi}_{n}}{p K}-\nu\right) & \text { if } \frac{\widetilde{\Pi}_{n}}{p K}-\nu \leq 0\end{cases}
$$

The distribution between dividends and investment depends on the expected net profits per capital unit $\widetilde{\Pi}_{n}$ compared with a standard of profitability $\nu$. If the expected net profit per capital unit $\widetilde{\Pi}_{n} /(p K)$ is higher than this standard, the producer increases his/her physical investments; if, on the contrary, the expected profit is lower than $\nu$, investments are reduced. Assuming that observed values are the best guess of expected values at each point in time leads to:

$$
\widetilde{\Pi}_{n}=\Pi_{n} .
$$

The extrema $\gamma_{\min }=0$ and $\gamma_{\max }=0.8$ of $\Gamma_{i n v}$ are parameters that represent, respectively, the positivity of investment and a cash-flow constraint.

The prognostic rule (A-16) for the evolution of the investment ratio $\Gamma_{i n v}$ can be interpreted using Tobin's (1969) $Q$ : if the future net profit is assumed equal to the current one and if the company value $V$ is equal to the discounted net profit flux, then $V=\Pi_{n} / \nu$, where $\nu$ here is the discount rate; $Q$ is then defined as the company value divided by its capital replacement value $p K$. In this approach, $Q$ drives the investment in the sense that investment progressively increases when $Q>1$ and 
decreases when $Q<1$.

The choice of $\nu$ determines the level of investment and thus the future production levels. In this article, $\nu$ is assumed to be constant at $3 \%$. This value of $\nu$ is smaller than the currently observed financial standard of profitability, because our model does not separate, at this stage, between private-sector investments, decided solely on the basis of financial profitability, and public-sector ones, which take additional considerations into account and have therefore, in general, lower internal return rates.

The model is calibrated so that the benchmark equilibrium is the economic balance of the European Union in 2001(EU-15), assuming that the economy was then in a steady state ${ }^{6}$.

\section{B Appendix: Modeling economic impacts of natural disasters}

Hallegatte et al. (2007b) argued at some length that modeling disaster consequences leads to several specific difficulties and requires the use of specific methods. Indeed, disasters mainly destroy the stock of productive capital and cause short-term disequilibria that have to be taken into account. A natural modeling option to represent disasters is to consider that they reduce instantaneously the total productive capital $K$ by an amount $\Delta K$.

To avoid underestimating natural disaster impacts because of decreasing returns in the production function (see Hallegatte et al., 2007b), we modified

$\overline{6}$ Obviously, the economy of EU-15 was not in a steady state in 2001, or at any other time; but this approximation is made acceptable by the weak sensitivity of the NEDyM behavior and of our results to small differences in the base-year equilibrium. 
the Cobb-Douglas production function by introducing a term $\xi_{K}$, which is the proportion of capital that was not destroyed. This new variable $\xi_{K}$ is such that the effective capital is $K=\xi_{K} \cdot K_{0}$, where $K_{0}$ is the potential productive capital, which is the stock of capital in the absence of any disaster. Instead of replacing $K$ by $\xi_{K} \cdot K_{0}$ in Eq. (A-2), we introduce the new production function:

$$
Y=\xi_{K} \cdot f\left(L, K_{0}\right)=\xi_{K} \cdot A \cdot L^{\lambda} \cdot K_{0}^{\mu}
$$

With this new function, a destruction of $x \%$ of the productive capital reduces production by $x \%$.

The replacement of the productive capital $K$ by the two new variables $K_{0}$ and $\xi_{K}$ makes it necessary to modify the modeling of investment and to introduce the distinction between regular investments, carried out to increase the production capacity, and reconstruction investments that follow a disaster. Denoting by $I_{n}$ the investments that increase the potential capital $K_{0}$, and by $I_{r}$ the reconstruction investments that increase $\xi_{K}$, we have:

$$
\begin{gathered}
\frac{\partial K_{0}}{\partial t}=\frac{-1}{\tau_{d e p}} K_{0}+\frac{I_{n}}{\xi_{K}}, \\
\frac{\partial \xi_{K}}{\partial t}=\frac{I_{r}}{K_{0}} .
\end{gathered}
$$

Short-term constraints, however, do play an important role in a disasters aftermath, by slowing down the reconstruction process (Hallegatte et al., 2007b). One such constraint is that consumers, insurance and re-insurance companies, as well as other companies and public organizations need time to direct high amounts of money to reconstruction activities. Another source of friction is 
that the sectors involved in reconstruction activities have skills and organizational capacities adapted to the normal state of affairs and cannot face huge increases in demand. Numerous examples of the importance of this effect are on the record; here are just three of these: (1) after the French winter storms in December 1999, reconstruction took several years because not enough roofers were available; (2) after the 2002 summer floods in Central Europe, for the same reason, reconstruction took 3 years, while losses represented only 10 days of German investments; and (3) in Florida, after the 2004 hurricane season, prices in the construction sector increased by up to 30 percent because qualified workers were scarce compared with the large boom in demand (Hallegatte et al., 2008).

To capture how these constraints may impact the pathways back to equilibrium, we bounded by $f_{\max }$ the fraction of total investment that reconstruction can mobilize.

$$
\left\{\begin{array}{l}
I_{n}=I-I_{r}, \\
I_{r}=\left\{\begin{array}{ll}
\operatorname{Min}\left(f_{\max } \cdot I,\left(1-\xi_{K}\right) \cdot K_{0}\right) & \text { if } \xi_{K}<1 \\
0 & \text { if } \xi_{K}=1
\end{array} .\right.
\end{array}\right.
$$

A value $f_{\max }=5 \%$ means that the economy can mobilize about $1 \%$ of GDP per year for the reconstruction, i.e. about 90 billion euros per year for EU-15. 


\section{References}

Albala-Bertrand, J., 1993. The Political Economy of Large Natural Disasters with Special Reference to Developing Countries. Oxford: Clarendon Press.

Benson, C., and E. Clay , 2004. Understanding the Economic and Financial Impact of Natural Disasters. The International Bank for Reconstruction and Development. The World Bank, Washington D.C.

Benhabib, J., and K. Nishimura, 1979. The Hopf-bifurcation and the existence of closed orbits in multi-sectoral models of optimal economic growth. Journal of Economic Theory 21, 421-444.

Bockarjova, M., A. Steenge, A. Van Der Veen, 2004. On direct estimation of initial damage in te case of major catastrophe; derivation of the basic equation. Disaster Prevention and Management 13 (4), 330-336.

Chiarella, C., and P. Flaschel, 2000. The Dynamics of Keynesian Monetary Growth. Cambridge University Press, 434 pp.

Chiarella C., P. Flaschel, and R. Franke, 2005. Foundations for a Disequilibrium Theory of the Business Cycle, Cambridge University Press, Cambridge, $523 \mathrm{pp}$.

Chiarella C., R. Franke, P. Flaschel, and W. Semmler, 2006. Quantitative and Empirical Analysis of Nonlinear Dynamic Macromodels, Elsevier, 277 pp.

Cochrane, H., 2004. Economic loss: myth and measurement. Disaster Prevention and Management 13, 290-296.

Copeland, T., and J. Weston, 2003. Financial Theory and Corporate Policy. 
Third Edition, Pearson Education International, Prentice Hall, Upper Saddle River, New Jersey, USA.

Day, R., 1982. Irregular growth cycles. American Economic Review 72, 406414.

Flaschel, P., R. Franke, and W. Semmler, 1997. Dynamic Macroeconomics: Instability, Fluctuations and Growth in Monetary Economies, MIT Press.

Frisch, R., 1933. Propagation Problems and Impulse Problems in Dynamic Economics. Economic Essay in honor of Gustav Cassel, George Allen and Unwin, London.

Gale, D., 1973. Pure exchange equilibrium of dynamic economic models. Journal of Economic Theory 6, 12-36.

Gali, J., 1999. Technology, employment, and the business cycle: Do technology shocks explain aggregate fluctuations? American Economic Review 89, 249271.

Gassebner, M., A. Keck and R. Teh, 2006. Shaken, not stirred: the impact of disasters on international trade, Working paper 06-139, KOF Swiss Economic Institute, ETH Zurich.

Gertler, M., and G. Hubbard, 1988. Financial Factors in Business Fluctuations, NBER Working Paper 2758.

Ghil, M., 1994: Cryothermodynamics: The chaotic dynamics of paleoclimate, Physica D, 77, 130-159.

Ghil, M., 2002. Natural climate variability, in Encyclopedia of Global Envi- 
ronmental Change, Vol. 1 (M. MacCracken \& J. Perry, eds.), Wiley \& Sons, Chichester/New York, 544-549.

Ghil, M., R. Benzi, and G. Parisi, 1985. Turbulence and Predictability in Geophysical Fluid Dynamics and Climate Dynamics, North-Holland Publ. Co., Amsterdam/New York/Oxford/ Tokyo, 449 pp.

Goodwin, R., 1951. The non-linear accelerator and the persistence of business cycles. Econometrica 19, 1-17.

Goodwin, R., 1967. A growth cycle. In C. Feinstein (Ed.), Socialism, Capitalism and Economic Growth, Cambridge University Press, Cambridge.

Grandmont, J.-M., 1985. On endogenous competitive business cycles. Econometrica 5, 995-1045.

Guckenheimer, J., and P. Holmes, 1987: Nonlinear Oscillations, Dynamical Systems, and Bifurcations of Vector Fields, 2nd edn., Springer-Verlag, New York/Berlin/Heidelberg/Tokyo.

Hahn, F., and R. Solow, 1995. A Critical Essay on Modern Macroeconomic Theory. The MIT Press, Cambridge, Massachussetts and London, England.

Hallegatte, S., 2008. An adaptive regional input-output model and its application to the assessment of the economic cost of Katrina. Risk Analysis, in press.

Hallegatte, S., M. Ghil, P. Dumas, and J.-C. Hourcade, 2007a. Business cycles, bifurcations and chaos in a neoclassical model with investment dynamics. Journal of Economic Behavior and Organization, in press. 
Hallegatte S., J.-C. Hourcade, and P. Dumas, 2007b. Why economic dynamics matter in assessing climate change damages: illustration on extreme events. Ecological Economics 62(2), 330-340.

Hallegatte S., A. Boissonnade, M.-E. Schlumberger, and R. Muir-Wood, 2008. Demand surge and worker migrations in disaster aftermaths: application to Florida in 2004 and 2005. Journal of Regional Science, submitted.

Harrod, R., 1939. An essay on dynamic economic theory. Economic Journal 49, 14-33.

Hicks, J., 1950. The cycle in outline, Ch. 8 in A Contribution to the Theory of the Trade Cycle. Oxford University Press, Oxford, pp. 95-107.

Hillinger, C., 1992. Cyclical Growth in Market and Planned Economies. Oxford University Press.

Hu, X. and F. Schiantarelli, 1998. Investment and Capital Market Imperfections: A Switching Regression Approach Using U.S. Firm Panel Data, The Review of Economics and Statistics 80, 466-479

Ireland, P. N., 2003. Endogenous money or sticky prices? Journal of Monetary Economics 50, 1623-1648.

Jarsulic, M., 1993. A nonlinear model of the pure growth cycle. Journal of Economic Behavior and Organization 22 (2), 133-151.

Jensen, M., 1986. Agency costs of free cash flow, corporate finance and takeovers. American Economic Review 76, 323-329.

Juglar, C., 1862. Des Crises Commerciales et leur Retour Périodique en France, 
en Angleterre, et aux Etats-Unis, Paris, Guillaumin et Cie, Librairies-Editeurs.

Kaldor, N., 1940. A model of the trade cycle. Economic Journal 50, 78-92.

Kalecki, M., 1937. A theory of the business cycle. Review of Economic Studies $4,77-97$.

Keynes, J.M., 1936. The General Theory of Employment, Interest and Money. Macmillan, London, 1967

Kimball, M.S., 1995. The quantitative analytics of the basic neomonetarist model, Journal of Money, Credit and Banking 27, 1241-1277

King, R., and S. Rebelo, 2000. Resuscitating real business cycles. In J. Taylor and M. Woodford (eds.), Handbook of Macroeconomics, North-Holland: Amsterdam, 927-1007.

Kydland, F. E., and E.C. Prescott, 1982. Time to build and aggregate fluctuations. Econometrica 50, 1345-70.

Lanzi, D., 2007. Capabilities, human capital and education, Journal of SocioEconomics 36, 424-435.

Loeuille, N., and M. Ghil, 2004. Intrinsic and climatic factors in North-American animal population dynamics. BMC Ecology 2004, 4:6, doi:10.1186/1472-67854-6.

Maynard Smith, J., and M. Slatkin, 1973. The stability of predator-prey systems, Ecology 54, 384-391.

Munich-Re, 2004. Topics. Annual Review: Natural Catastrophes 2003. Munich Reinsurance Group, Geoscience Research Group, Munich, Germany. 
Nikaido, H., 1996. Prices, Cycles, and Growth. MIT Press, Cambridge, MA, $285 \mathrm{pp}$.

Nordhaus, W.D., 2006. Geography and macroeconomics: New data and new findings, Proceedings of the National Academy of Sciences 103 (10), 35103517.

Okuyama, Y., 2004. Modeling spatial economic impacts of an earthquake: Input-Output approaches. Disaster Prevention and Management 13 (4), 297306.

Ricardo, D., 1810. The High Price of Bullion, a Proof of the Depreciation of Bank Notes, London: John Murray.

Rose, A., J. Benavides, S. E. Chang, P. Szczesniak, and D. Lim, 1997. The regional economic impact of an earthquake: direct and indirect effects of electricity life-line disruptions. Journal of Regional Science 37, 437-458.

Rotemberg, J., and M. Woodford, 1994. Is the business cycle a necessary consequence of stochastic growth? National Bureau of Economic Research, Working paper No. 4650

Samuelson, P., 1939. A synthesis of the principle of acceleration and the multiplier. Journal of Political Economy 47, 786-797.

Samuelson, P., 1974. A biological least-action principle for the ecological model of Volterra-Lotka. Proc. Nat. Acad. Sci. U.S.A., 71, 3041-3044.

Smith, A., 1776. An Inquiry into the Nature and Causes of the Wealth of Nations. Reprinted London: Methuen, 5th edn., Ed., E. Cannan, 1904. 
Slutsky, E., 1927. The summation of random causes as a source of cyclic processes, III(1), Conjuncture Institute, Moscow, Reprinted in Econometrica 5, 105-146.

Solow, R., 1956. A contribution to the theory of economic growth. The Quarterly Journal of Economics 70 (1), 65-94.

Tavares, J., 2004. The open society assesses its enemies: shocks, disasters and terrorist attacks. Journal of Monetary Economics, Elsevier 51(5), 1039-1070.

Tol, R., 2002a. New estimates of the damage costs of climate change, Part I: Benchmark estimates. Environmental and Resource Economics 21 (1), 47-73. Tol, R., 2002b. New estimates of the damage costs of climate change, Part II: Dynamic estimates. Environmental and Resource Economics 21 (2), 135-160. Tobin, J., 1969. A general equilibrium approach to monetary policy. Journal of Money, Credit and Banking 1, 15-29.

West, C., and D. Lenze, 1994. Modeling the regional impact of natural disasters and recovery: a general framework and an application to hurricane Andrew, International Regional Science Review 17(2), 121-150.

World Bank, 1999. Turkey: Marmara earthquake assessment, World Bank Working Paper. 